\title{
1D Numerical modelling of dam break using finite element method
}

\author{
Nur Lely Hardianti Zendrato ${ }^{1, *}$, Dhemi Harlan², Mohammad Bagus Adityawan ${ }^{2}$, and Dantje Kardana Natakusumah ${ }^{2}$ \\ ${ }^{1}$ Magister Sttudy Program of Civil Engineering, Faculty of Civil and Environmental Engineering, Institut Teknologi Bandung, \\ Bandung, Indonesia \\ ${ }^{2}$ Center for Water Resources Development, Institute for Research and Community Services, Institut Teknologi Bandung, Bandung, \\ Indonesia
}

\begin{abstract}
In numerical modeling, dam break is one case that has its own challenges, because shock wave is found in the dam break modeling that usually provides a numerical instability. Usually, dam break problem is solved by Saint Venant equation using a finite difference method with artificial dissipation or Total Variation Diminishing (TVD) filter. But in this research, finite element method and the finite difference method are used. To verify the accuracy of the model, a comparison against the Stoker analytical method for dam break case was performed. Numerical modeling of dam break is required to find out the collapse area, thus it is used for determining mitigation that can be done in the area, related to dam safety. In numerical modeling, oscillation or numerical instability often occurs, for which special treatment is required to reduce or eliminate the oscillations. In this research, the treatment for that case is a Hansen filter for both methods. From the simulation result, it is found that Hansen filter is sensitive in reducing oscillation depending on the correction factor value and $\Delta t$ that used. For dam break case, after filter applied, the value of Pearson Correlation Coefficient of Taylor Galerkin and Mac-Cormack methods are 0.999 . The error rate for a Taylor Galerkin method are $0.118 \%$ at $t=3 \mathrm{~s}$ and $0.123 \%$ at $t=10 \mathrm{~s}$. The error rate for Mac-Cormack method are $0.043 \%$ at $t=3 \mathrm{~s}$ and $5.048 \%$ at $t=10$ s. From the comparison of the model, it can be concluded that Taylor Galerkin finite element method proved to be capable and more accurate in simulating dam break compared to Mac-Cormack finite difference method.
\end{abstract}

\section{Introduction}

The river is a part that can not be separated from our life that bring benefits not only to humans but also to all living things on the world. One of them as a source of water that can be used for drinking water, irrigation and the others. With increasing human population will lead to an increased need for water, for it is necessary to use water effectively and efficiently through the construction of buildings such as the weir or dam.

However, that constructions can also give negative impact for human life such as if there is a failure of the dam. Dam failure is usually caused by several factors, namely geotechnical failure, strength of construction, excess pore water pressure, quality of material, planning errors and factors of natural disasters such as landslides, earthquakes and other factors.

Dam failure will disrupt the water supply, electricity supply, infrastructure damage, as well as causing significant environmental damage. Therefore, it required an initial planning as laboratory tests or numerical modelling in the design of the planned dam to prevent the failure of the weir/dam.

Dam Break is similar to tsunami propagation as they are both long waves. The effect to surrounding area can be devastating. Laboratory experiment [1] may provide details of the phenomenon, however laboratory testing has the disadvantage of not being able to do variations on modeling, because the test takes a long time and high cost. Therefore numerical modeling is needed that can be modeled with a variety of more complex cases, thus saving time and costs.

To reduce the oscillation in the model, [2] use filter to maintain stability of the calculation. Filter function as artificial dissipation, which will be made filters for each time step at each point.

Numerical model used in this study is Taylor Galerkin finite element method is a combination of the Galerkin finite elemen method and Taylor series. Moreover, finite difference is also used in this research to compare it with finite element method. In this case, Mac-Cormack finite difference method is chosen because Mac-Cormack

\footnotetext{
* Corresponding author: nurlelyhardiantizendrato@gmail.com
} 
scheme is more accurate in modelling that the others scheme [3,4].

This study aimed to reveal how accurate the result of the calculation using Taylor Galerkin applied in cases dam break. While the purpose of this study are: 1) Conduct an analysis of numerical model are benchmarked to the analytic method and numerical testing; and 2) Analyze the effect of applying filter on Taylor Galerkin scheme and Mac-Cormack scheme to reduce the oscillation in the modeling results.

By reviwing and modelling is expected to show the collapse area, thus it is used for determining mitigation that can be done in the area, related to dam safety.

\section{Literature review}

\subsection{Properties and characteristics of fluid}

The fluid is defined as a substance that deforms continuously for affected a shear stress [5]. A shear stress is formed when a tangential force is working on a surface.

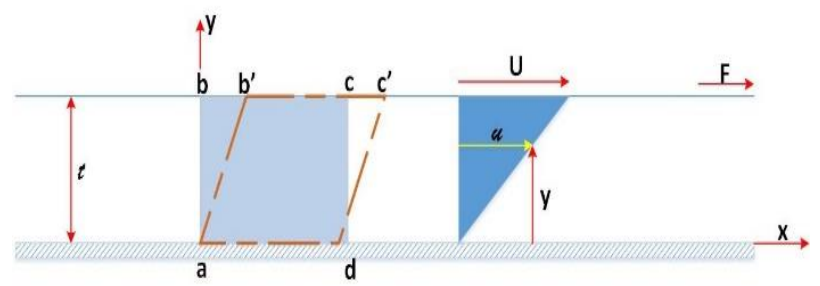

Fig. 1. Deformations caused by the application of a constant frictional force

(Source: Fluid Mechanics, 1987)

Fluid is classified as follows:

1. Newton fluid, there is a linear relationship between the magnitude of the applied shear stress and rate of deformation as a result, as shown in Figure 2.

2. Non-Newton fluid, there is a nonlinear relationship between the magnitude of the applied shear stress and rate of angular change.

3. Ideal Fluid, is incompressible fluid and nonviscous (invicid), so there is no shear resistance which causes tangential slipping. The forces working on the ideal fluid lies on the boundary surface with the normal direction of surface.

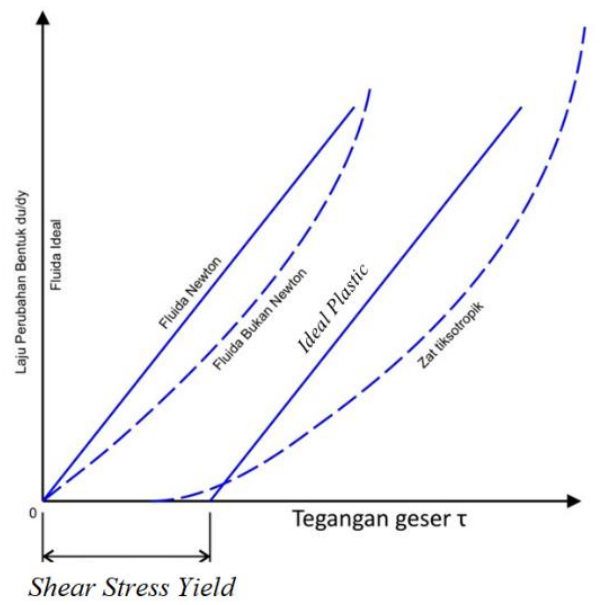

Fig. 2. Diagram rheological

(Source: Fluid Mechanics, 1987)

\subsection{Saint venant equations}

The first step, define the volume control is symbolized $\Omega$, i.e. water volume in the review field [6]. This approach is commonly used in fluid mechanics caused the process easier to use volume control, because it is difficult to identify and follow the system of fluid particles. Furthermore, it can be illustrated as shown below:

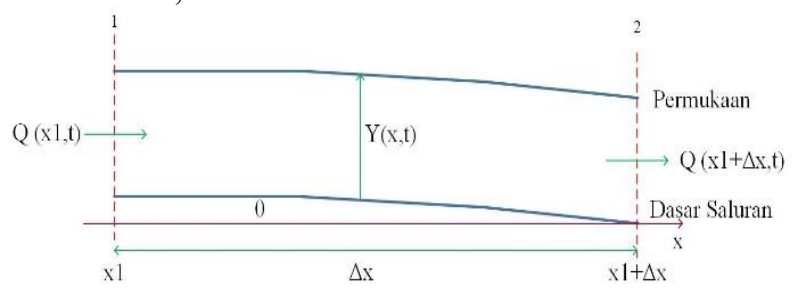

Fig. 3. The cross-section in open channels

From the equation of mass conservation and momentum conservation are applied to control volume, by substituting the forces acting on the control volume based on Newton's second law is obtained an average depth of one-dimensional as follows:

$$
\begin{gathered}
\frac{\partial \mathrm{A}\left(\mathrm{x}_{1}, \mathrm{t}\right)}{\partial \mathrm{t}}+\frac{\partial \mathrm{Q}\left(\mathrm{x}_{1}, \mathrm{t}\right)}{\partial \mathrm{x}}=0 \\
\frac{\partial \mathrm{Q}\left(\mathrm{x}_{1}, \mathrm{t}\right)}{\partial \mathrm{t}}+\frac{\partial}{\partial \mathrm{x}}\left[\frac{\mathrm{Q}^{2}\left(\mathrm{x}_{1}, \mathrm{t}\right)}{\mathrm{A}\left(\mathrm{x}_{1}, \mathrm{t}\right)}\right]+\mathrm{gA}\left(\mathrm{x}_{1}, \mathrm{t}\right)\left(\frac{\partial \mathrm{Y}\left(\mathrm{x}_{1}, \mathrm{t}\right)}{\partial \mathrm{x}}+\mathrm{S}_{\mathrm{f}}\left(\mathrm{x}_{1}, \mathrm{t}\right)-\right. \\
\left.\mathrm{S}_{\mathrm{b}}\left(\mathrm{x}_{1}\right)\right)=0
\end{gathered}
$$

Equation (1) is continuity equation and equation (2) is a momentum equation. These two equations are called the Saint-Venant equations.

\subsection{Numerical methods}

Numerical methods is commonly used in the technical field consists of a finite difference method, finite element method and finite volume method. These third method are used to obtain an approximation function. However, in this study only focused on two methods: the finite element method and finite difference method. Here is the difference between the two methods in space approximation:

\section{Finite difference method}

In the picture below, if the function is solved using the finite difference method, the oscillations that occur is difficult to predict. This is because finite different methods produce approximation solutions at nodal points. So, to obtain more accurate solution, then the number of nodal points is reproduced by minimized $\Delta \mathrm{x}$.

\section{Finite element method}

The finite element method is numerical method used to obtain the solution of differential equations. Completion using this method, produces an approximation solution in the form of a function on each element such that these functions are continuous with each other. Here's an example of completion using the finite element method and its comparison with finite difference method: 


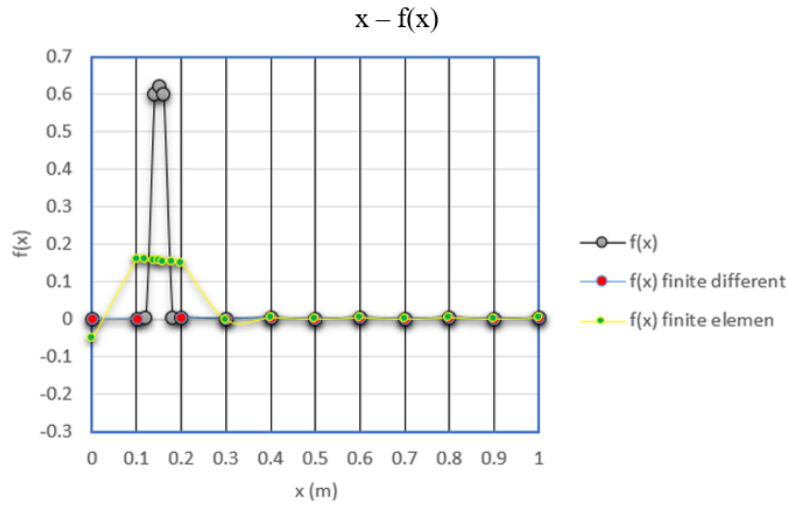

Fig. 4. Comparison results use finite elemen method dan finite difference method.

In the above picture is shown that for a function that is close to zero, the function approximation is generated using the finite difference method is inaccurate. While that better reflect the actual function is a function approximation resulting from the calculation using the finite element method. The advantages of the finite element method that makes the author choose to use this method to analyze the dam break case.

\section{Numerical modelling}

In general, the conservation equation is as follows:

$$
\frac{\partial U}{\partial t}+\frac{\partial F_{i}}{\partial x_{i}}=\frac{\partial R_{d i}}{\partial x_{i}}+R_{S}
$$

where $U$ is independent variables vector, $F$ is convective flux vector, $\mathrm{Rd}$ is diffusion rate vector, $\mathrm{Rs}$ is source vector, $\mathrm{t}$ is time, and $\mathrm{x}$ is space.

The conservation equation is applied to the case of dam break.

\subsection{Governing equation}

For dam break case, the hydrodynamic equations applies which consist of mass conservation equations (continuity) and momentum conservation. If expressed in vector form, the equations above can be expressed as follows [7]:

$$
\begin{gathered}
\mathrm{U}=\left\{\begin{array}{c}
\mathrm{H} \\
\mathrm{HU} \\
0
\end{array}\right\} \\
F_{x}=\left\{\begin{array}{c}
H U \\
H U^{2}+\frac{1}{2} g\left(H^{2}-h^{2}\right) \\
0
\end{array}\right\} \\
R_{d}=\left\{\begin{array}{c}
2 \mathrm{v}_{t} H \frac{\partial U}{\partial x} \\
0
\end{array}\right\} \\
0 \\
R_{s}=\left\{\begin{array}{c}
g \eta \frac{\partial h}{\partial x}-\frac{g|U| U}{C_{c}^{2}} \\
0
\end{array}\right\}
\end{gathered}
$$

\subsection{Governing Equation Discretization with Taylor Galerkin Finite Element Method}

By using the general conservation equation in (3) and applying Taylor Galerkin discretization, the following equation is obtained:

$$
\begin{aligned}
& (M \Delta U)=\Delta t\left\{\int _ { \Omega } \left\{\left[R_{s i}^{n} N_{i}+\left(R_{s}^{n+1 / 2}-\bar{R}_{s}^{n}\right)\right] N_{j}+\left[F_{k}^{n+1 / 2}-\bar{F}_{k}^{n}+F_{i}^{k^{n}} N_{i}-\right.\right.\right. \\
& \left.\left.\left.R_{d k}^{n}\right] \frac{\partial N_{j}}{\partial x_{k}} d \Omega\right\}+\int_{\Gamma} R_{d n}-F_{i n} N_{i}^{n}-\left[F^{n+1 / 2}-\bar{F}^{n}\right] N_{j} d \Gamma\right\}
\end{aligned}
$$

where:

Index $\mathrm{i}$ and $\mathrm{j}=$ function of the $\mathrm{i}$ and $\mathrm{j}$

$\mathrm{k}$ Index $\quad=\mathrm{k}$-space

$\mathrm{M} \quad=$ consistent mass matrix

$\mathrm{U}=$ vector of independent variables is a

function of the position $\mathrm{x}$ and time $\mathrm{t}$

$\mathrm{fk} \quad=$ convective flux vector in $\mathrm{k}$-space coordinates

Rs $\quad=$ source depending on the $\mathrm{x}$

$\mathrm{Ni}, \mathrm{Nj} \quad=$ linear shape functions for nodes $\mathrm{i}$ and $\mathrm{j}$

Equation (8) can be written in the simple form as follows:

$$
[M]\{\Delta U\}=\{f\}
$$

Where $[M]$ is the mass matrix that can be either consistent or lumped mass matrix.

By considering the nature of the linear form function in each element (piecewise linear approximation), the terms in equation (8) can be translated as follows:

$\Delta U M^{e}=\left[\begin{array}{cccccc}\frac{h^{e}}{3} & 0 & 0 & \frac{h^{e}}{6} & 0 & 0 \\ 0 & \frac{h^{e}}{3} & 0 & 0 & \frac{h^{e}}{6} & 0 \\ 0 & 0 & \frac{h^{e}}{3} & 0 & 0 & \frac{h^{e}}{6} \\ \frac{h^{e}}{6} & 0 & 0 & \frac{h^{e}}{3} & 0 & 0 \\ 0 & \frac{h^{e}}{6} & 0 & 0 & \frac{h^{e}}{3} & 0 \\ 0 & 0 & \frac{h^{e}}{6} & 0 & 0 & \frac{h^{e}}{3}\end{array}\right]\left[\begin{array}{c}\Delta U 1_{i} \\ \Delta U 2_{i} \\ \Delta U 3_{i} \\ \Delta U 1_{i+1} \\ \Delta U 2_{i+1} \\ \Delta U 3_{i+1}\end{array}\right]$

$R_{s} \int_{0}^{h^{e}} N_{i} N_{j} d x=\left[\begin{array}{cccccc}\frac{h^{e}}{3} & 0 & 0 & \frac{h^{e}}{6} & 0 & 0 \\ 0 & \frac{h^{e}}{3} & 0 & 0 & \frac{h^{e}}{6} & 0 \\ 0 & 0 & \frac{h^{e}}{3} & 0 & 0 & \frac{h^{e}}{6} \\ \frac{h^{e}}{6} & 0 & 0 & \frac{h^{e}}{3} & 0 & 0 \\ 0 & \frac{h^{e}}{6} & 0 & 0 & \frac{h^{e}}{3} & 0 \\ 0 & 0 & \frac{h^{e}}{6} & 0 & 0 & \frac{h^{e}}{3}\end{array}\right]\left[\begin{array}{c}R_{s} 1_{i} \\ R_{s} 2_{i} \\ R_{s} 3_{i} \\ R_{s} 1_{i+1} \\ R_{s} 2_{i+1} \\ R_{s} 3_{i+1}\end{array}\right]$

$$
\int_{0}^{h^{e}}\left(R_{s}^{n+\frac{1}{2}}-\overline{R_{s}}\right) N_{j} d x=\frac{h^{e}}{2}\left[\begin{array}{l}
R 1_{s}^{n+\frac{1}{2}}-\overline{R 1_{s}} \\
R 2_{s}^{n+\frac{1}{2}}-\overline{R 2_{s}} \\
R 3_{s}^{n+\frac{1}{2}}-\overline{R 3_{s}} \\
R 1_{s}^{n+\frac{1}{2}}-\overline{R 1_{s}} \\
R 2_{s}^{n+\frac{1}{2}}-\overline{R 2_{s}} \\
R 3_{s}^{n+\frac{1}{2}}-\overline{R 3_{s}}
\end{array}\right]
$$




$$
\begin{gathered}
\int_{0}^{h^{e}}\left(F_{x}^{n+1 / 2}\right) \frac{\partial N_{j}}{\partial x} d x=\left[\begin{array}{c}
-F 1_{x}^{n+\frac{1}{2}} \\
-F 2_{x}^{n+\frac{1}{2}} \\
-F 3_{x}^{n+\frac{1}{2}} \\
F 1_{x}^{n+\frac{1}{2}} \\
F 2_{x}^{n+\frac{1}{2}} \\
F 3_{x}^{n+\frac{1}{2}}
\end{array}\right] \\
\int_{0}^{h^{e}} \bar{F}_{x}^{n} \frac{\partial N_{j}}{\partial x} d x=\frac{1}{2}\left[\begin{array}{c}
-\left(F_{x} 1_{i}^{n}+F_{x} 1_{i+1}^{n}\right) \\
-\left(F_{x} 2_{i}^{n}+F_{x} 2_{i+1}^{n}\right) \\
-\left(F_{x} 3_{i}^{n}+F_{x} 3_{i+1}^{n}\right) \\
F_{x} 1_{i}^{n}+F_{x} 1_{i+1}^{n} \\
F_{x} 2_{i}^{n}+F_{x} 2_{i+1}^{n} \\
F_{x} 3_{i}^{n}+F_{x} 3_{i+1}^{n}
\end{array}\right] \\
\int_{0}^{h^{e}} F_{x}^{n} N_{i} \frac{\partial N_{j}}{\partial x} d x=\frac{1}{2}\left[\begin{array}{c}
-\left(F_{x}^{n} 1_{1}+F_{x}^{n} 1_{1+1}\right) \\
-\left(F_{x}^{n} 2_{1}+F_{x}^{n} 2_{1+1}\right) \\
-\left(F_{x}^{n} 3_{1}+F_{x}^{n} 3_{1+1}\right) \\
F_{x}^{n} 1_{1}+F_{x}^{n} 1_{1+1} \\
F_{x}^{n} 2_{1}+F_{x}^{n} 2_{1+1} \\
F_{x}^{n} 3_{1}+F_{x}^{n} 3_{1+1}
\end{array}\right] \\
\int_{0}^{h^{e}}\left(R_{d x}^{n}\right) \frac{\partial N_{j}}{\partial x} d x=\left[\begin{array}{l}
-R_{d} 1_{x}^{n} \\
-R_{d} 2_{x}^{n} \\
-R_{d} 3_{x}^{n} \\
R_{d} 1_{x}^{n} \\
R_{d} 2_{x}^{n} \\
R_{d} 3_{x}^{n}
\end{array}\right]
\end{gathered}
$$

Variables with superscript $n+1 / 2$ are obtained by using algorithms Lax-Wendroff. Substitution of the equation $(\mathrm{X})$ - (Y) into the equation $(\mathrm{Z})$ yields the following matrix equation:

$$
\frac{h^{e}}{6}\left[\begin{array}{llllll}
2 & 0 & 0 & 1 & 0 & 0 \\
0 & 2 & 0 & 0 & 1 & 0 \\
0 & 0 & 2 & 0 & 0 & 1 \\
1 & 0 & 0 & 2 & 0 & 0 \\
0 & 1 & 0 & 0 & 2 & 0 \\
0 & 0 & 1 & 0 & 0 & 2
\end{array}\right]\left[\begin{array}{c}
\Delta U 1_{i} \\
\Delta U 2_{i} \\
\Delta U 3_{i} \\
\Delta U 1_{i+1} \\
\Delta U 2_{i+1} \\
\Delta U 3_{i+1}
\end{array}\right]=
$$

$$
\begin{aligned}
& \Delta t\left\{\frac{h^{e}}{6}\left[\begin{array}{cccccc}
2 & 0 & 0 & 1 & 0 & 0 \\
0 & 2 & 0 & 0 & 1 & 0 \\
0 & 0 & 2 & 0 & 0 & 1 \\
1 & 0 & 0 & 2 & 0 & 0 \\
0 & 1 & 0 & 0 & 2 & 0 \\
0 & 0 & 1 & 0 & 0 & 2
\end{array}\right]\left[\begin{array}{c}
R_{s} 1_{i} \\
R_{s} 2_{i} \\
R_{s} 3_{i} \\
R_{s} 1_{i+1} \\
R_{s} 2_{i+1} \\
R_{s} 3_{i+1}
\end{array}\right]+\frac{h^{e}}{2}\left[\begin{array}{c}
R 1_{s}^{n+\frac{1}{2}}-\overline{R 1_{s}} \\
R 2_{s}^{n+\frac{1}{2}}-\overline{R 2_{s}} \\
R 3_{s}^{n+\frac{1}{2}}-\overline{R 3_{s}} \\
R 1_{s}^{n+\frac{1}{2}}-\overline{R 1_{s}} \\
R 2_{s}^{n+\frac{1}{2}}-\overline{R 2_{s}} \\
R 3_{s}^{n+\frac{1}{2}}-\overline{R 3_{s}}
\end{array}\right]+\right. \\
& \left.\left[\begin{array}{c}
-F 1_{x}^{n+\frac{1}{2}} \\
-F 2_{x}^{n+\frac{1}{2}} \\
-F 3_{x}^{n+\frac{1}{2}} \\
F 1_{x}^{n+\frac{1}{2}} \\
F 2_{x}^{n+\frac{1}{2}} \\
F 3_{x}^{n+\frac{1}{2}}
\end{array}\right]-\left[\begin{array}{c}
-R_{d} 1_{x}^{n} \\
-R_{d} 2_{x}^{n} \\
-R_{d} 3_{x}^{n} \\
R_{d} 1_{x}^{n} \\
R_{d} 2_{x}^{n} \\
R_{d} 3_{x}^{n}
\end{array}\right]\right\}
\end{aligned}
$$

To complete the matrix equation is used iteration method involving a consistent mass matrix $(\mathrm{M})$ and a lumped mass matrix (ML) as follows:

$$
\begin{gathered}
M_{L} \Delta U^{k+1}=f^{n}-\left(M-M_{L}\right) \Delta U^{k} \\
\Delta U^{k+1}=M_{L}^{-1} f^{n}-M_{L}^{-1} M \Delta U^{k}+\Delta U^{k}
\end{gathered}
$$

where $\mathrm{M}$ is the consistent mass matrix and lumped mass matrix ML is as follows:

$$
\begin{gathered}
M=\frac{h^{e}}{6}\left[\begin{array}{llllll}
2 & 0 & 0 & 1 & 0 & 0 \\
0 & 2 & 0 & 0 & 1 & 0 \\
0 & 0 & 2 & 0 & 0 & 1 \\
1 & 0 & 0 & 2 & 0 & 0 \\
0 & 1 & 0 & 0 & 2 & 0 \\
0 & 0 & 1 & 0 & 0 & 2
\end{array}\right] \\
M_{L}=\frac{h^{e}}{6}\left[\begin{array}{llllll}
3 & 0 & 0 & 0 & 0 & 0 \\
0 & 3 & 0 & 0 & 0 & 0 \\
0 & 0 & 3 & 0 & 0 & 0 \\
0 & 0 & 0 & 3 & 0 & 0 \\
0 & 0 & 0 & 0 & 3 & 0 \\
0 & 0 & 0 & 0 & 0 & 3
\end{array}\right]
\end{gathered}
$$

\subsection{Governing Equation Discretization with Mac- Cormack Finite Difference Method}

Discretization finite difference is based on the Taylor series expansion to approximate the magnitude of a variable in the partial derivative equation. In the MacCormack finite difference scheme, two calculation steps are carried out, namely the predictor step is forward difference approximation, and the corrector step is backward difference approximation. The result of the calculation is average of the calculation of the predictor and corrector steps. Discretization carried out in this scheme can be seen in more detail in Zendrato et al. [3].

\section{Results and discussion}

The following are input parameters used in the modeling:

$$
\begin{array}{ll}
\mathrm{L} & =1000 \mathrm{~m} \\
\mathrm{Hu} & =10 \mathrm{~m} \\
\mathrm{hd} & =0.1 \mathrm{~m} \\
\Delta \mathrm{x} & =\text { varied } \\
\text { Viscosity } & =0
\end{array}
$$

Channels are assumed to be flat $(\mathrm{S} 0=0)$, the effect of the friction is negligible and eliminates diffusion rate. This is because calibration this model using the Stoker analytical method, no friction and no turbulence, so the source and diffusion rate are zero.

In the above case, the amount to be searched is the value of the water level at any point being reviewed. The modeling requirement is that the depth of the water is not too deep so that the flow velocity distribution used is uniform vertical direction.

After modeling using Taylor Galerkin schemes, it is necessary to verify the results obtained from the modeling. In this study the authors verified using Stoker analytical method [8]. There are several assumptions used 
by Stoker, namely: 1) Dam break occurs suddenly; 2) Flat channels base; and 3) There is no friction.

Initial conditions:

with,

$$
h(x)= \begin{cases}h_{l} & \text { untuk } 0 m \leq x \leq x_{0} \\ h_{r} & \text { untuk } x_{0}<x \leq L\end{cases}
$$

$$
h_{l} \geq h_{r} \operatorname{dan} u(x)=0 \frac{\mathrm{m}}{\mathrm{s}}
$$

Water level $\mathrm{h}$, is given as follows:

$$
\begin{aligned}
& h(t, x)=\left\{\begin{array}{c}
\frac{4}{9 g}\left(\sqrt{g h_{l}}-\frac{x-x_{0}}{2 t}\right)^{2} \\
\frac{c_{m}^{2}}{g} \\
h_{r}
\end{array}\right.
\end{aligned}
$$

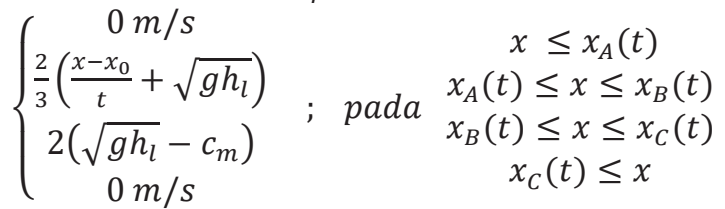

where:

$$
\begin{gathered}
x_{A}(t)=x_{0}-t \sqrt{g h_{l}} \\
x_{B}(t)=x_{0}+t\left(2 \sqrt{g h_{l}}-3 c_{m}\right) \\
x_{C}(t)=x_{0}+t \frac{2 c_{m}^{2}\left(\sqrt{g h_{l}}-c_{m}\right)}{c_{m}^{2}-g h_{r}}
\end{gathered}
$$

with: $c_{m}=\sqrt{g h_{m}}$ where $\mathrm{h}_{\mathrm{m}}$ should be between hd and hu. So with $\mathrm{hm}, \mathrm{c}_{\mathrm{m}}$ initial value can be known then substituted to the following equation:

$-8 g h_{r} c_{m}^{2}\left(\sqrt{g h_{l}}-c_{m}\right)^{2}+\left(c_{m}^{2}-g h_{r}\right)^{2}\left(c_{m}^{2}+g h_{r}\right)=0$

So that the equation is zero. For ease of understanding, Stoker analytical methods can be described as shown below :

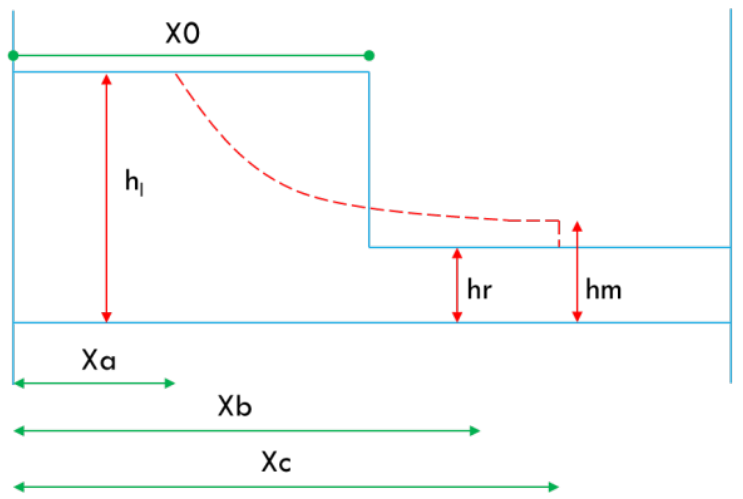

L

Fig. 5. Water surface profiles before and after dam-break

From the above input data, is obtained water surface profile without applying the filter as follows:

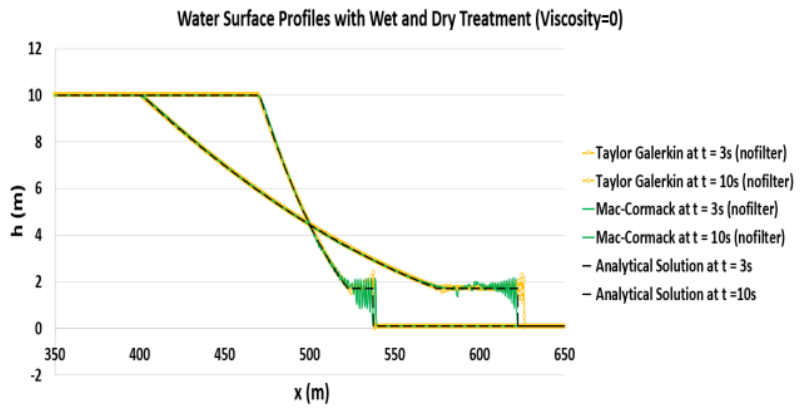

Fig. 6. Comparison of water level profile changes between Taylor Galerkin Finite Element Method and Mac-Cormack Different Methods (nofilter)

When viewed from the above figure, dam break modeling results still show oscillations due to the shock wave in the downstream of the dam, although the collapse of the resulting pattern is same with the analytic solution. Therefore, it is necessary to add a filter to the model where in this study the authors use the Hansen filter [2]: Orde 1:

$$
h(i)=f_{k} * h(i)+\left(1-f_{k}\right) \frac{[h(i+1)+h(i-1)]}{2}
$$

Orde 2:

$h(i)=f_{k} * h(i)+\frac{2}{3}\left(1-f_{k}\right) \frac{[h(i+1)+h(i-1)]}{2}+\frac{1}{3}\left(1-f_{k}\right) \frac{[h(i+2)+h(i-2)]}{2}$

The correction factor value used in this study is $\mathrm{fk}=$ 0.99 and Order 1. Because after several experiments with varying values is obtained correction factor $\mathrm{fk}$ that most stable is 0.99 .

To ensure numerical stability, especially in the downstream oscillation section of the dam, a treatment is done so that the scalar variable is not negative, using an algorithm similar to the application of wet and dry.

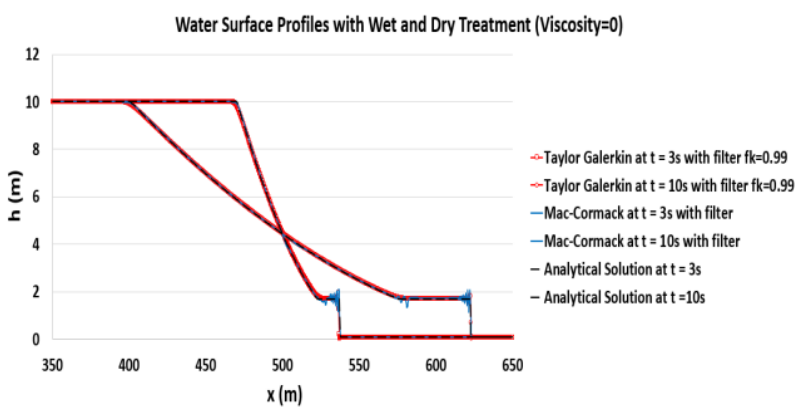

Fig. 7. Comparison of water level profile changes between Taylor Galerkin Finite Element Method and Mac-Cormack Finite Different Methods (with filter)

From the picture above, it is illustrated that there are oscillations in the water level profiles resulting from calculations using the finite difference method. So, it is evident that the water surface profiles generated through the calculation using the finite element method provides more satisfactory results than using finite difference method. However, from the modeling results above it is necessary to test the level of compatibility between the modeling results using Taylor Galerkin and MacCormack on the Stoker analytical method. The suitability level testing method used in this study is the Pearson 
Correlation Coefficient method. Pearson Correlation Coefficient is a measure of linear correlation between two variables $\mathrm{x}$ and $\mathrm{y}$. Pearson Correlation Coefficient has a value between +1 and -1 , where +1 is a positive linear correlation, 0 has no linear correlation and -1 is a total negative linear correlation. In addition, the author quantifies the error value to find out the different simulation results with experimental data, which can be seen in the table below:

Table 1. The test table of suitability level with previous studies (Stoker's analytic) and quantification of error values

\begin{tabular}{|c|c|c|c|c|c|}
\hline \multirow[b]{2}{*}{ No } & \multirow[b]{2}{*}{ Variable } & \multicolumn{2}{|c|}{ Pearson Correlation } & \multicolumn{2}{|c|}{ Error (\%) } \\
\hline & & $\begin{array}{c}\text { Taylor } \\
\text { Galerkin }\end{array}$ & $\begin{array}{c}\text { Mac- } \\
\text { Cormack }\end{array}$ & $\begin{array}{c}\text { Taylor } \\
\text { Galerkin }\end{array}$ & $\begin{array}{c}\text { Mac- } \\
\text { Cormack }\end{array}$ \\
\hline 1 & $\begin{array}{l}\text { Water Level } \\
\text { Change }(\mathrm{t}=3 \\
\text { s) }\end{array}$ & 0.99979 & 0.99997 & 0.11866 & 0.04333 \\
\hline 2 & $\begin{array}{l}\text { Water Level } \\
\text { Change }(\mathrm{t}=10 \\
\mathrm{s})\end{array}$ & 0.99982 & 0.99995 & 0.12286 & 5.04845 \\
\hline
\end{tabular}

In the table above is shown that the two methods: Taylor Galerkin finite element method and Mac-Cormack finite difference method already showed results close to 1. This means that the level of conformity on the calculation/pattern in water level changes for both methods already showing results equal or close to the experimental results. However, if viewed from the percentage of errors, which have the highest error rate is the method of Mac-Cormack at $\mathrm{t}=10 \mathrm{~s}$ with $\varepsilon=5048 \%$. It can be concluded, modeling using Taylor Galerkin finite element method more satisfactory results than the Mac-Cormack finite difference method.

\section{Conclusions}

From this study it can be concluded as follows:

1. For dam break case at time step $3 \mathrm{~s}$ and $10 \mathrm{~s}$, have described the results as Stoker analytic solutions (the upstream), where the special treatment is made by extending the domain modeling, addition of filter, applying variation of the correction factor to the filter, wet and dry and eliminates the diffusion rate / turbulent. In this case simulations that produce a satisfactory water surface profile is the domain length $1000 \mathrm{~m}$ with $\Delta \mathrm{x}=0.25$ around the dam and it's viscosity is 0 .

2. The Average error value of the dam break calculation using the finite element method is $0: 11 \%-$ a $0.12 \%$, while for mac-Cormack is greater that is $0-5 \%$. In addition the Pearson correlation value is 0.999 which means that it is close to one or coinciding with analytic solution.

3. Comparison of water level profiles resulting from the calculation using finite element method is better and coincides with the Stoker analytic results compared with the finite difference method, because finite different method has oscillation even though the filter has been added.

This research is supported by the Program Penelitian, Pengabdian kepada Masyarakat, dan Inovasi (P3MI), Institut Teknologi Bandung.

\section{References}

1. Y. Mitobe, M. B. Adityawan, H. Tanaka, T. Kawahara, T. Kurosawa dan K. Otsushi, Experiments on Local Scour Behind Coastal Dikes Induced by Tsunami Overflow, Coastal Engineering Proceedings (2014)

2. M. B. Adityawan and H. Tanaka, Bed Stress Assessment Under Solitary Wave Run-Up, Earth Planets Space, 64, 945-954 (2012)

3. N. L. H. Zendrato, A. Chrysanti, B. P. Yakti, M. B. Adityawan, Widyaningtias and Y. Suryadi, Application of Finite Difference Schemes to $1 D$ St. Venant for Simulating Weir Overflow, The Third International Conference on Sustainable Infrastructure and Built Environment (SIBE) 2017, MATEC Web of Conferences, 147, 03011 (2018)

4. M. Farid, B. P. Yakti, A. Rizaldi and M. B. Adityawan, Finite Difference Numerical Scheme for Simulating Dam Break Flow, The $5^{\text {th }}$ HATHI International Seminar on Water Resilience in a Changing World (2016)

5. B. R. Munson, D. F. Young and T.H. Okiishi, Fundamentals of fluid mechanics fourth edition, Department of Aerospace Engineering and Engineering Mechanics, Department of Mechanical Engineering, USA (2002)

6. X. Litrico and V. Fromion, Modeling and control of hydrosystems, Springer Science \& Business Media, London (2009)

7. D. Harlan, Analisis fenomena di perairan dangkal dengan menggunakan Metode Elemen Hingga Taylor Galerkin, Tesis Program Magister, Institut Teknologi Bandung (1998)

8. O. Delestre, C. Lucas, P.A. Ksinant, F. Darboux, C. Laguerre, T. N. T. Vo, F. James, and S. Cordier. $A$ Compilation of Shallow Water Analytic Solutions for Hydraulic and Environmental Studies (2016) 